\title{
Potential Role for the Gut Microbiota in Modulating Host Circadian Rhythms and Metabolic Health
}

\author{
Shanthi G. Parkar $1, * \mathbb{C}$, Andries Kalsbeek ${ }^{2,3}\left[\right.$ and James F. Cheeseman ${ }^{4}$ \\ 1 The New Zealand Institute for Plant \& Food Research Limited, Private Bag 11600, \\ Palmerston North 4442, New Zealand \\ 2 Department of Hypothalamic Integration Mechanisms, Netherlands Institute for Neuroscience, \\ Royal Netherlands Academy of Arts and Sciences, Meibergdreef 47, 1105BA Amsterdam, The Netherlands; \\ a.kalsbeek@nin.knaw.nl \\ 3 Department of Endocrinology and Metabolism, Amsterdam UMC, University of Amsterdam, \\ Meibergdreef 9, 1105AZ Amsterdam, The Netherlands \\ 4 Department of Anaesthesiology, University of Auckland, Private Bag 92019, Auckland 1142, New Zealand; \\ j.cheeseman@auckland.ac.nz \\ * Correspondence: shanthi.parkar@plantandfood.co.nz; Tel.: +64-6-9537-737, Fax: +64-6-3517-050
}

Received: 17 January 2019; Accepted: 28 January 2019; Published: 31 January 2019

check for updates

\begin{abstract}
This article reviews the current evidence associating gut microbiota with factors that impact host circadian-metabolic axis, such as light/dark cycles, sleep/wake cycles, diet, and eating patterns. We examine how gut bacteria possess their own daily rhythmicity in terms of composition, their localization to intestinal niches, and functions. We review evidence that gut bacteria modulate host rhythms via microbial metabolites such as butyrate, polyphenolic derivatives, vitamins, and amines. Lifestyle stressors such as altered sleep and eating patterns that may disturb the host circadian system also influence the gut microbiome. The consequent disruptions to microbiota-mediated functions such as decreased conjugation of bile acids or increased production of hydrogen sulfide and the resultant decreased production of butyrate, in turn affect substrate oxidation and energy regulation in the host. Thus, disturbances in microbiome rhythms may at least partially contribute to an increased risk of obesity and metabolic syndrome associated with insufficient sleep and circadian misalignment. Good sleep and a healthy diet appear to be essential for maintaining gut microbial balance. Manipulating daily rhythms of gut microbial abundance and activity may therefore hold promise for a chrononutrition-based approach to consolidate host circadian rhythms and metabolic homeorhesis.
\end{abstract}

Keywords: sleep/wake rhythm; gut microbiome; plant food; prebiotics; clock genes; chronodisruption

\section{Introduction}

Human metabolism is adapted to a circadian rhythm of $\sim 24 \mathrm{~h}$ that is synchronized to the Earth's $24 \mathrm{~h}$ light/dark cycle. This rhythm is orchestrated by the brain's central clock in the hypothalamic suprachiasmatic nucleus, which in turn synchronizes peripheral clocks in the rest of the body (Figure 1). These clocks exist in almost every cell, and are comprised of a highly conserved set of core clock genes including period 1/2/3 (Per1/2/3), the brain and muscle aryl hydrocarbon receptor nuclear translocator-like 1 (Bmal1), cryptochrome 1/2 (Cry1/2), and the circadian locomotor output cycles kaput gene (Clock). This molecular clock mechanism plays an important role in regulating the rhythmic expression of clock-controlled genes, which in turn regulate the synthesis, storage, and expenditure of energy [1]. The light/dark cycle is the most potent Zeitgeber (an external or environmental cue that entrains the endogenous clock rhythms) for the central clock. Peripheral clocks may also be entrained by behavioral cues such as feeding and exercise [1,2]. 


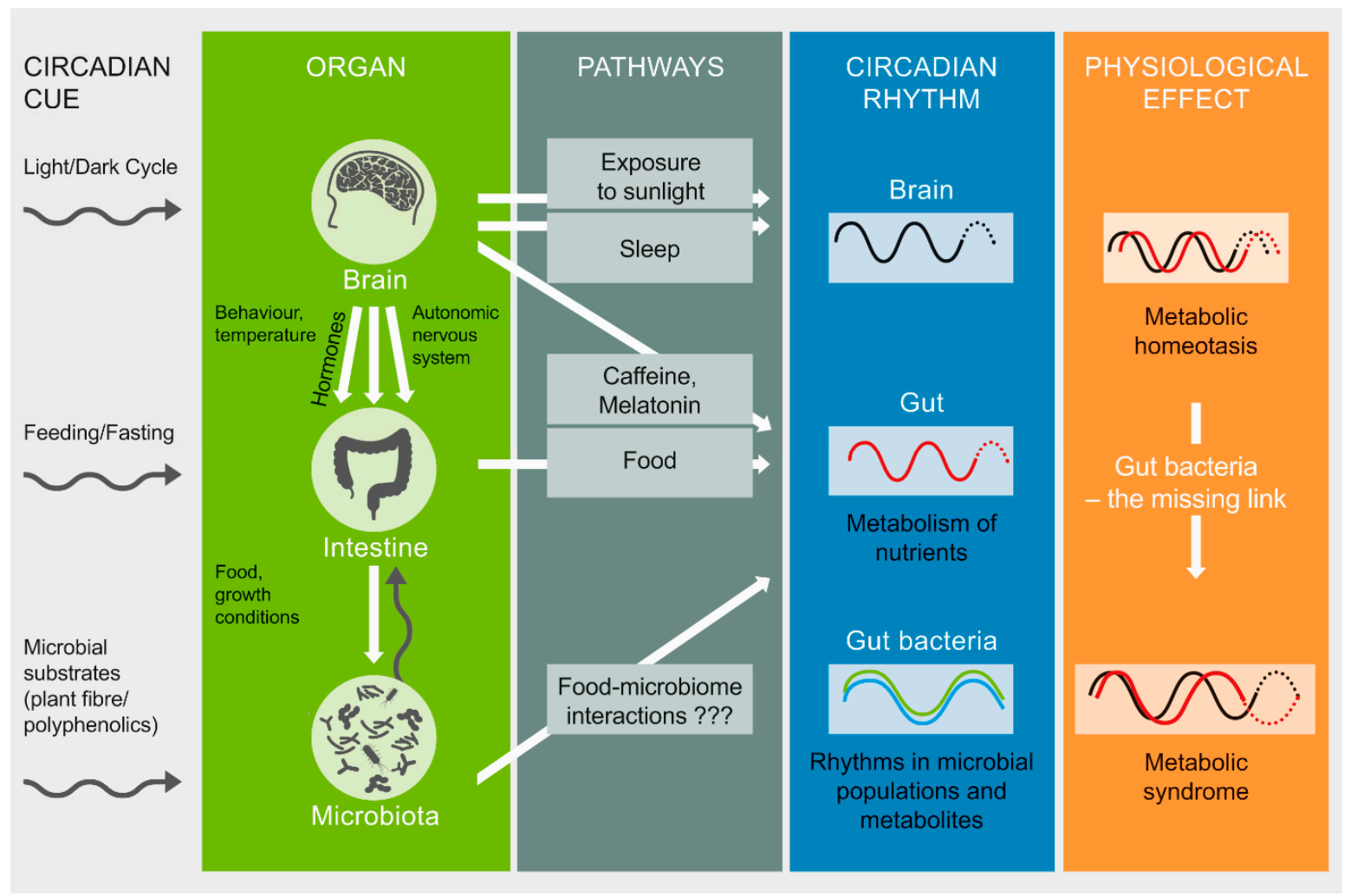

Figure 1. Circadian rhythm, gut microbiota, and metabolism. The light/dark cycle is the Zeitgeber for the central clock in the brain, while signals from the brain entrain peripheral clocks, e.g., in the intestine. Intestinal bacteria also show diurnal fluctuations in terms of their abundance and functions. Host controlled behaviors such as sleep, diet (food composition, timing of eating a meal), light exposure, and stimulants (e.g., caffeine) may potentially affect intestinal rhythms of metabolism. New evidence indicates that gut microbiota influences circadian rhythms, with consequent impact on the metabolic homeostasis of the host (Figure adapted from [1]).

The 24/7 lifestyles of shift work, early morning starts, delayed bedtimes, jet lag, and late night eating may cause circadian disruption, as our internal clocks may fail to keep pace with the conflicting information of the external light/dark cycle and our behavior in an optimal way. This misalignment of the rhythms that control our energy metabolism increases the risks of weight gain and metabolic syndrome, including type 2 diabetes mellitus [3,4]. Interestingly, an imbalance in our intestinal microbiota is also associated with obesity and diabetes [5-8].

The intestine affects our energy status by controlling physiological functions such as digestion and absorption of food, and gastric emptying - activities that are also regulated by clock genes [9]. The human intestine harbors a 10 trillion-cell microbial community that increases in abundance and diversity along the cephalocaudal axis with niche-specific variations in the spatial architecture of bacteria in the gut lumen and mucosal wall [10]. The five major bacterial phyla are Firmicutes, Bacteroidetes, Actinobacteria, Proteobacteria, and Verrucomicrobia, of which the former two constitute the vast majority, at relative abundances ranging up to $65 \%$ of total bacteria [11].

The single most abundant genus is Bacteroides (phylum Bacteroidetes), which thrives in the distal gut due to its metabolic flexibility, i.e., ability to break down a range of carbohydrates from dietary sources to host-derived mucins, thereby generating mainly acetate, succinate, and propionate $[5,12]$. Firmicutes, though poorer in carbohydrate breakdown enzymes, are enriched in genes involved in intracellular transport of nutrients including sugars [5]. This phylum, the most abundant genus of which is Faecalibacterium from the family Ruminococcaceae, generates most of the butyrate, which sustains the growth and integrity of colonic epithelial cells [11,12]. Actinobacteria, the third most 
abundant phylum, includes Bifidobacterium, which is considered a probiotic organism due to its versatility in terms of metabolizing dietary carbohydrates and ability to inhibit pathogens [11,12]. Of the low abundance phyla, Proteobacteria include commensal bacteria, many of which act as opportunistic pathogens $[11,13,14]$; while Verrucomicrobia, represented by the mucin-degrading Akkermansia muciniphila, is associated with improvement in metabolic health [15]. The human gut can comprise up to 1000 species, the number and proportions of which vary with a number of factors including mode of birth, age, gender, body mass, diet, health status, intake of medications especially antibiotics, activity, and travel $[10,11,16]$. This microbiome encodes about 5 million genes, which is $\sim 100$-fold greater than the human genome. The microbial metagenome includes the highly abundant machineries for carbohydrate degradation and utilization, synthesis of vitamins, detoxification of xenobiotics to the low abundance pathways for bile and sulfur metabolism. These functions are contained across multiple species that form a co-operative network to transform ecological niches to maximize survival of the microbial community $[5,11,14]$.

The objective of this review is to explore the connections between gut microbiota and circadian rhythms by examining current literature using a set of questions to guide our understanding (Table 1). In the first part, we discuss current evidence on the gut microbiome-circadian rhythm interactions under different scenarios of circadian stress. In the second part, we examine gut microbiota-based mechanisms that may potentially protect hosts against the pathological manifestations of circadian disruption.

Table 1. Guiding queries used to examine gut microbiome-circadian interactions.

\begin{tabular}{|c|c|c|}
\hline Query & Conditions & Examples of Evidences \\
\hline \multirow{3}{*}{$\begin{array}{l}\text { How does circadian rhythm } \\
\text { affect gut microbiota? }\end{array}$} & Light/dark cycles & $\begin{array}{l}\text { Effect of diurnal variation and altered light/dark } \\
\text { cycles on gut microbiome }\end{array}$ \\
\hline & Sleep status & $\begin{array}{l}\text { Gut microbiome in sleep deprivation/sleep } \\
\text { fragmentation }\end{array}$ \\
\hline & Diet & High fat diet, night eating \\
\hline \multirow{3}{*}{$\begin{array}{l}\text { How does gut microbiota } \\
\text { affect circadian rhythm? }\end{array}$} & $\begin{array}{l}\text { Antibiotic-induced gut } \\
\text { microbial alterations }\end{array}$ & $\begin{array}{l}\text { Do antibiotics affect sleep or circadian-controlled } \\
\text { metabolic states? }\end{array}$ \\
\hline & $\begin{array}{l}\text { Microbial dysbiosis due to } \\
\text { intestinal disease }\end{array}$ & $\begin{array}{l}\text { Chronic gut disorders with altered microbiota } \\
\text { showing co-morbidities in sleep }\end{array}$ \\
\hline & Microbial metabolites & $\begin{array}{c}\text { Short chain fatty acids, Secondary bile acids } \\
\text { Vitamins } \\
\text { Biogenic amines } \\
\text { Hydrogen sulfide }\end{array}$ \\
\hline
\end{tabular}

\section{Factors Implicated in Gut Microbiome-Circadian Rhythm Interactions}

In this section, we discuss external cues such as light/dark cycles and the consequent exposure to sunlight; and host-associated cues such as sleep and diet, on circadian-microbiome interactions with consequent effects on the host.

\subsection{Light/Dark Cycles}

Day/night rhythmicity has been seen in 20-83\% of mice gut microbial taxa [17], much like the circadian oscillations seen in up to $50 \%$ of the mouse transcriptome [18]. Feeding restricted to the active dark phase resulted in a cyclical rhythm in the mouse gut microbiome, with Firmicutes peaking during feeding and decreasing during daytime fasting with a peak-to-trough ratio of 3:1. Bacteroidetes and Verrucomicrobia peaked during the daytime fasting period [17], potentially due to their greater ability to forage on intestinal mucin glycans [19]. Both dark phase and ad libitum feeding in mice, maintained dark phase peaks in Bacteroidales and light phase peaks in Lactobacillales and Clostridiales, along with expected increases in Firmicutes-associated functions such as detoxification of toxins, metabolism of vitamins, and environmental sensing, while the microbial rhythms were reversed by light-phase 
only feeding [20]. Such analysis of microbial abundance is generally expressed as relative abundance of different bacteria in a sample. Similar phyla-level rhythmicities were also observed in terms of relative abundance in male and female ad libitum-fed mice on 12/12 light/dark cycles, although the rhythmicities were more pronounced for female mice [21]. When comparing the data using the measure of absolute abundance of the bacterial groups, inferred from the product of relative abundance with the measured bacterial load, new patterns emerged. Diurnal oscillations were unchanged in Bacteroidetes, but lost in Firmicutes for both male and female mice, and the much less abundant Proteobacteria also showed light phase peaks in male mice [21]. These different mouse studies indicate that the peaks in Firmicutes during the dark phase are diet-driven, while blooms in Bacteroidetes, Verrucomicrobia, and Proteobacteria during the light phase were due to the cessation of feeding. One may thus conclude that periods of fasting are critical for ensuring the representation of bacteria that are otherwise outcompeted by the increase of Firmicutes after meal times, to break down dietary carbohydrates that reach the colon.

The diurnal rhythmicity of the microbial community is driven by the population dynamics of individual players and presence of their food. The more abundant Firmicutes thrive in response to the supply of dietary glycans and then their populations decrease when the food source is exhausted. The host intestinal mucosa is the major source of glycans during the rest phase. Bacteroidetes then dominate as they feed upon the host glycans using their wider repertoire of glycases, and penetrate deeper into host gut mucosal barriers [20,21]. Benefits to the host accrue in terms of energy and other growth factors such as vitamins, synthesized indigenously by the commensals. Consistent with this display of mutualism, ad libitum mice in normal light/dark cycles eat mainly in the dark phase, and this behavior resulted in an increase in the dark phase in microbial pathways related to energy metabolism, DNA repair, and cell growth. Furthermore, light phase resting led to an increase in microbial pathways related to chemotaxis and motility required for the mucus-adherent bacteria to reach closer to the intestinal wall [20,22].

Rhythmicity in bacterial adherence to the gut wall was influenced by multiple host factors. The effect of host's feeding patterns was evident when microbial rhythmicity was phase-reversed by restricting the feeding to the light-phase in wild-type mice [20]. An intact host rhythm was also inferred to be important when gut microbial rhythmicity was lost in ad libitum-fed Per1/2 deficient mice [20]. However, again light-phase feeding restored microbial rhythms, indicating that host-controlled feeding behaviors, such as time-restricted feeding or fasting, can restore the rhythmicity lost after an impairment of the host's clock machinery. A host circadian-gene control of the microbial rhythmicity of Bacteroidales, Clostridiales, and Lactobacillales, all major taxonomical orders in terms of function and abundance, was also inferred by the significant changes in their abundance in Bmal1-knockout mice [21]. However, this was most likely a consequence of rhythm loss in (feeding) behavior. Furthermore, examining the role of gender in microbiome rhythmicity, Liang et al. observed that female mice show a more pronounced amplitude for Bacteroidetes rhythms indicating potential hormonal influences on microbiota structure. This gender bias was much more subtle after Bmal1-deletion, detectable only at lower taxa levels [21]. Gut microbiota was affected in mice with mutations in the clock genes Per1/2 (loss of microbial rhythms) and Clock ${ }^{\Delta 19}$ (loss of microbial richness and diversity), indicating a central role for host clock-controlled mechanisms in regulating gut microbiota [20,23]. Host clock-driven immune response mechanisms may also be responsible for gating the microbial community. For instance, the higher sensitivity of mice on 12/12 light/dark cycles to infection with the pathogen Salmonella enterica serovar Typhimurium in the early rest phase at Zeitgeber time 4 (i.e., ZT4, which is $4 \mathrm{~h}$ after lights on) rather than ZT16 (i.e., $4 \mathrm{~h}$ after lights off) [24]. How reversed feeding/fasting cycles, and the consequent light-phase peaking of the much more abundant Firmicutes may potentially outcompete the proteobacterial pathogens such as salmonella, was not explored in this study. This may be an interesting study given that the acidic by-products of metabolism by Firmicutes groups such as lactobacilli are known to selectively inhibit the growth of enteropathogens such as Salmonella [12,25]. 
Circadian disruption for a period of four weeks based on a regime of constant light exposure was also studied in ad libitum-fed mice. It was found to increase Ruminococcus torques and decrease Lactobacillus johnsonii, organisms that may have roles in impairing and protecting the integrity of intestinal barrier, respectively [26]. In the same study, bacterial metatranscriptomics data further demonstrated an increase in genes involved in the synthesis and transportation of endotoxin lipopolysaccharides, and decrease in genes that confer immune benefits to the host [26]. The role of light exposure on gut microbiota was also studied by subjecting ad libitum-fed mice to constant darkness for two weeks [27]. According to the authors, constant darkness disrupted microbial rhythmicity in both small and large intestinal segments, but sampling was not performed according to circadian time and the figures indicate a free-running rhythm rather than disruption. The authors also reported a significant clostridial bloom in the foregut. However, in both the light/light and dark/dark study, feeding activity, i.e., the key driver of microbial rhythms was not monitored. Light/dark cycles may thus influence the diurnal rhythms in resident commensals, but most likely this is by changing the feeding rhythm of the host.

Rhythms in microbiome composition and metabolic activity have also been demonstrated in a human study which factored in clock time, and the timing and caloric density of the meals. In this study with 28 volunteers (male:female, 1:1), faeces samples were collected during normal waking hours between 07:30 and 22:00 h [28]. Over the day, butyrate producers, Lachnospira, Roseburia, and Eubacterium spiked earlier in response to the substrates made available due to the intake of food and decreased as the energy source was depleted after microbial utilization. Other bacterial groups that emerged earlier in the day included primary feeders that survive by rapid but incomplete breakdown of the carbohydrate to generate acetate and lactate (such as Eggerthella), the bile-tolerant groups (such as Oscillospira and Bilophila, that thrive in the post-prandial bile-rich intestinal milieu), and the $\mathrm{H}_{2} \mathrm{~S}$ producing Desulfovibrio (in response to the increased lactate, and the sulfur from the bile taurocholates) [28,29].

As the intake of food decreased throughout the day, there was a shift in the gut microbiome, with a corresponding decrease in microbial metabolic processes that utilize the carbon sources to generate short chain fatty acids (SCFAs). Overnight fasting increased the SCFA propionate as the microbiota re-structured its community to forage on host-derived glycans [19]. Although faecal samples were not collected over the night period, this study demonstrated the effect of the clock time on gut microbial balance in humans.

\subsection{Sunlight Exposure}

Light/dark cycles are well-recognized to be the most important cue for entrainment of the central clock in all mammals, including humans [1].

Insufficient exposure to sunlight might also affect us in other ways (as explained below), which potentially involve our gut microbiota. Exposure to the sun's UV rays is essential for dermal synthesis of 25-hydroxyvitamin D (25-OHD, vitamin D3) which then enters systemic circulation [30]. Low levels of circulating vitamin D3 have been associated with visceral adiposity, which in turn increases susceptibility to insulin resistance and inflammation [31]. Vitamin D3 was found to increase the protective ileal mucus, which serves as an anchor for many beneficial bacteria including Akkermansia muciniphila, and also protects against colonization (and consequently breakdown of intestinal barrier) by opportunistic pathogens, such as adherent-invasive Escherichia coli [32-34]. Diet and supplementation with vitamin D3 for eight weeks was found to improve the gut microbial balance and richness in the upper gut (rather than the hindgut) in a small study of 16 healthy volunteers. There was a relative decrease in proteobacterial pathobionts such as Pseudomonas spp. and Escherichia/Shigella spp. [35]. Thus, circulating vitamin D3 levels can influence intestinal biogeography, and thereby microbial colonization. Further studies are required to investigate the effect of sunlight on the gut microbiome, and potential mediation of this effect by vitamin $D$. 


\subsection{Sleep}

Insufficient sleep, duration, quality or timing, due to $24 / 7$ schedules (e.g., jet lag, shift work) or choices (delayed bedtimes, lack of physical activity), and sleep disorders (sleep apnoea, narcolepsy), are associated with increased weight gain and impaired energy balance, glucose tolerance, and insulin sensitivity [3]. Sleep disturbance and the profound effect on circadian disruption contribute to these metabolic health outcomes [36].

Gut bacteria have been implicated in the regulation of sleep for nearly half a decade. In line with this, a study in rats showed that depletion of gut microbiota using antibiotics reduced slow wave sleep [37]. The effect of the broad-spectrum antibiotics, minocycline and amipicillin was studied in healthy male students $(n=19)$. Minocycline, but not ampicillin, reduced slow wave sleep for up to three consecutive nights after administration of the antibiotic, although there were no significant changes in sleep latency, nor wake after sleep onset [38]. Given the vast complexity of the gut microbiome in terms of composition, abundance, niche-specific, and consortia-specific resistance to antibiotics, it is difficult to correlate the role of specific bacterial groups with the regulation of sleep, let alone specific stages of sleep. Further studies are warranted to confirm microbiota-mediated effects on sleep given that minocycline is known to exert neuroprotective and anti-inflammatory effects on the central nervous system [39], which may potentially interact with the circadian system.

An overgrowth of Gram-positive lactic acid bacteria results in the accumulation of D-lactate, which has been hypothesized to cause neurotoxic effects after crossing the blood-brain barrier [40]. Conversely, controlling the excessive accumulation of circulating D-lactate may therefore help to stabilize neurological symptoms. This hypothesis was tested in a human study where erythromycin (more effective against Gram positive bacteria) was given for six days to 22 patients (five male) with chronic fatigue syndrome. Faecal streptococci decreased significantly in seven participants, which correlated with improved sleep in terms of total sleep duration and sleep onset latency, and better subjective mood measures [40].

A preferential overgrowth of streptococci and other oropharyngeal, and colonic microflora has been observed in the gastrointestinal disorder, small intestinal bacterial overgrowth [41]. This microbial overgrowth has been implicated in the pathogenesis of restless legs syndrome, a sleep-related movement disorder, that typically worsens in the evening [42]. Indeed, bacteria or their cell components may be the cause of the inflammation seen with this disorder [16]. More study is warranted to investigate the connection between gut microbiome and the symptoms presented in sleep- and circadian-related disorders.

How the gut microbiota is affected by sleep is of increasing interest given the integral role of microbiota in metabolic wellness. In one randomized crossover study with nine male volunteers, just two nights of partial sleep deprivation of $4 \mathrm{~h}$ (sleep opportunity $0245-0700 \mathrm{~h}$ ), significantly decreased insulin sensitivity compared to normal sleep (22:30-07:00 h) during baseline, and after two days of sleep recovery. There were also significant changes to microbial populations that have been associated with a disturbed metabolism and even obesity (increased Coriobacteriaceae, Erysipelotrichaceae, and Firmicutes: Bacteroidetes ratio and decreased Tenericutes) [43]. However, a longer term study of two episodes of five nights of sleep restriction (sleep between 04:00-08:00 h), separated by five nights of $12 \mathrm{~h}$ sleep, with a final $12 \mathrm{~h}$ sleep recovery for two nights, did not show changes in the faecal microbial composition at baseline, during sleep restriction or after sleep recovery [44]. While both these studies were conducted in environmentally controlled laboratories, the latter study included both males and females (total $n=11$ ), and collected faecal samples between 08:00-14:00 $\mathrm{h}$ to factor in for microbial rhythms. In the same study, the authors also conducted a $4 \mathrm{~h}$-sleep restriction study in rats, subjected to seven days of forced activity in slowly rotating drums for $20 \mathrm{~h}$. This sleep restriction did not alter any of the major phyla (compared to baseline), although it did increase a pro-inflammatory candidate phylum TM7-3a that was not restored after four days of sleep recovery. However, this regime of sleep restriction may not have caused sufficient disruption of the hosts' circadian rhythms, which is emerging as a potential link to gut microbial rhythms. Chronic sleep disruption or sleep fragmentation 
such as that seen in sleep apnoea, also have an impact on body mass and insulin sensitivity. In a recent study in mice, four weeks of sleep fragmentation increased food intake and caused visceral adiposity and inflammation [45]. Overall, sleep fragmentation caused a shift in the major microbial phyla of the gut, lowering Actinobacteria by $50 \%$ and Bacteroidetes by $20 \%$, and increasing Firmicutes by $20 \%$, a profile characteristic of obese gut microbiota $[10,16]$. Significant changes were noted after two weeks of sleep fragmentation. There was a change in the relative abundance of two Firmicutes families, i.e., Lachnospiraceae (increase) and Lactobacillaceae (decrease). This microbial profile continued throughout the duration of sleep fragmentation protocol, although the bacterial abundance reverted to normal after two weeks of recovery from poor sleep. Circadian-sleep-gut microbiome connections were also inferred using metabolomic studies. Fifteen men volunteered for $24 \mathrm{~h}$ of sleep deprivation after a normal sleep/wake cycle with 8 h of sleep, under controlled conditions of light, sleep, meals, and posture. Acute sleep deprivation caused an increase in urinary metabolites, including those generated by gut bacteria. For example, acetate and 3-indoxyl sulfate, trimethylamine-N-oxide, p-cresol sulfate, and 3-hydroxyisobutyrate (generated by microbial breakdown of tryptophan, choline, tyrosine and valine respectively) [46].

Clearly, more studies are required to understand the connection between gut microbiota and modern lifestyles, which encompass inter-related factors i.e., sleep issues, circadian disturbances, stress, and poor dietary regimes that are well-recognized microbial manipulators. Indeed, dietary stressors such as alcohol or fat were found to exacerbate the gut microbiome disturbances caused by circadian disruption $[23,47]$. Light/dark shifts in mice on a diet containing alcohol increased the trend towards intestinal inflammation and polyposis, which at least partly may be contributed to by the increased Firmicutes: Bacteroidetes ratio that was driven by decreased Allobaculum and increased Bacteroides [48].

\subsection{Jet Lag}

Transmeridian or frequent multi-time-zone travel causes jet lag, a syndrome manifested by delayed physiological adaptation to rapid changes in time zone. The subjective effects of jet lag include poor mood, concentration, and bowel movement [49]. While there are multiple factors such as sleep, hormone rhythms, and dietary intake that are changed during jet lag, recent studies have demonstrated relationships between jet lag, gut microbial dysbiosis, and dysfunctional metabolic homeostasis.

In one study, mice were subjected to four months of a simulated jet lag-multiple repeats of three days of an $8 \mathrm{~h}$ light cycle advance, followed by three days of the original light/dark cycle. Simulation of jet lag for four months did not significantly change the overall food intake, but did cause an increased weight gain and impaired glucose tolerance [20]. There was also a significant impact on gut microbiota and its functions, for example, the abundance and the rhythm of this abundance was suppressed for one of the major butyrate producing families, Ruminococcaceae. Broad-spectrum antibiotics given to jet lagged mice with gut dysbiosis rescued them from these metabolic changes, indicating a potential role for gut bacteria in inducing the metabolic pathologies of jet lag. That the effect of these dysbiotic microbial landscapes extended beyond the gut was proven when faeces from the time-shifted mice induced glucose intolerance in germ-free non-jet lagged mice [20]. It is thus possible that the loss of rhythms in microbially-mediated pathways associated with energy extraction and host maintenance contributed to this metabolic disruption.

Short sleep duration on work days with sleeping in on free days, has resulted in the modern phenomenon of social jetlag [50]. In a cohort of 817 individuals, this social jetlag has been associated with predisposition to metabolic syndrome due to obesity, elevated glycated haemoglobin (a marker of prolonged elevation of blood glucose and consequent type 2 diabetes), and systemic inflammation [51]. While this study has not examined the impact on gut microbiota, changes in microbiome composition have been associated with these metabolic states. Gut microbial dysbiosis and the ensuing inflammation, and loss of intestinal integrity are postulated to be key mechanisms in causing metabolic disruption [52]. Dysbiotic patterns in diabetic individuals showa decreased 
Bacteroidetes, and changes in key Firmicutes such as lowered Ruminococcaceae, Lachnospiraceae, Faecalibacterium prausnitzii, and increased Lactobacillus indicates the putative connections between bacterial diversity (and functionality) and metabolic regulation of blood glucose [7,8].

\subsection{Diet and Dietary Patterns}

Circadian rhythms in the intestine are entrained both by the central clock and by food/eating patterns, and amongst others regulate the hosts' intestinal cell transcription of the transport proteins required for uptake and absorption of the energy giving nutrients, glucose, amino acids, and triglycerides [9].

During undisturbed daily rhythm, for most humans, consumption of food will coincide with the activity phase, which in turn is synchronized with the light phase of the light/dark cycle, with consequent effects on the rhythms of circulating metabolites [53,54]. In a pilot study where 10 healthy male volunteers were subjected to $40 \mathrm{~h}$ of constant wakefulness, with enforced posture, dim light and hourly isocaloric meals, about $15 \%$ of the systemic metabolites displayed a circadian periodicity despite the lack of typical feeding/fasting routines, light/dark or sleep/wake cycles. The metabolites that peaked around subjective lunch-time were mainly lipid breakdown products such as fatty acids in the plasma and protein break down products, i.e., amino acids in the saliva [54]. This study, much like what may happen in a long-haul flight followed by a switch to a different time zone, indicates the inherent persistence of the internal clocks and metabolic features. The gut microbiota was not investigated in this study; although microbial populations have been shown to display periodicity in other studies in mice and humans $[17,20,28]$.

While the central clock in the brain's suprachiasmatic nucleusis a light-entrainable oscillator, peripheral oscillators (other parts of the brain, liver, gut, muscle, etc.) may be entrained by food, temperature or other factors, and even uncoupled from the suprachiasmatic nucleus by, for instance, restricted feeding during the sleep phase [1,2]. Indeed, the feeding regime is a powerful entrainer of peripheral clocks in metabolic tissues such as liver and intestine [2].

The feeding regime affects diurnal oscillations not just in body clocks, but also in the resident gut microbiota. A high-fat diet was found to alter oscillations in the brain, liver, and adipose tissue of clock genes and clock-controlled genes [55]. A high-fat diet was also shown to induce changes in the composition of the microbiome, the transplantation of which was able to induce obesity in germ-free mice [16]. In another study, a diet rich in fat and sugar exacerbated the effects of circadian disruption on the gut microbiota, with a drastic reduction of microbial diversity and the Firmicutes/Bacteroidetes ratio, mainly by promoting different bacteria from the Firmicutes phylum, most significantly Ruminococcaceae, altogether representing a microbiome such as that seen in obesity $[10,16,47]$. This gut microbial profile has also been observed in teenagers who consumed high sugar and fat diets [56]. A 20\% increase in Firmicutes with a corresponding decrease in Bacteroides was associated with an increased energy harvest of $150 \mathrm{kcal} /$ day, and this may be attributed to the differences in their genomic machinery to utilize and assimilate the substrates that reach the colon [57]. An energy surplus of this quantum over a year might result in body weight gain of about $5 \mathrm{~kg}$ per year. In conclusion, altered light/dark or sleep/wake cycles will have a profound influence on feeding patterns and circadian disruption, as the food that reaches the bowel would arguably be the primary driver for the changes in microbial growth. Thus, more studies are required to examine microbiome profiles that are a function of the geophysical cycle as opposed to feeding rhythms.

Host diet has been known to rapidly alter the resident gut microbial composition and diversity $[10,58,59]$. Two major components that resist small intestinal digestion and reach the large intestine to regulate the host gut microbiome are the plant food-derived fiber and polyphenols $[60,61]$. Plant-based fiber and polysaccharides promote a butyrate-rich environment by enhancing proficient carbohydrate degrading bacteria from families such as Lachnospiraceae (Roseburia), Eubacteriaceae (Eubacterium rectale), and Ruminococcaceae (Ruminococcus bromii), as compared to fiber-poor, animal-based diets, that favor the more bile tolerant Alistipes, Bacteroides, and Bilophila, that are 
more capable of protein breakdown [58]. When Per2::Luc (luciferase reporter gene fused to Per2 gene) knock-in mice fed ad libitum with low fiber-containing chow were then shifted to diets containing $5 \%$ of the rapidly fermentable cellobiose or the slowly fermentable cellulose, there were significant effects on entrainment of peripheral Per 2 rhythms. The cellobiose-fed mice showed significant phase advances of Per 2 rhythm in the liver and kidney within 1 day, which was further increased on day 2. Cellulose, which is recalcitrant to microbial degradation, caused significant Per2 phase advances only at the end of day 2, due to the slower build-up of SCFAs. Per2 phase advances were seen even in submandibular salivary glands, albeit significantly only at day 2 [62].

Diet rich in galactooligosaccharides, polydextrose, lactoferrin, and milk fat globule membrane, components that are known to enhance beneficial bacteria, when administered to 24-day-old rats, was found to reduce the impact of stressor-exposure on gut microbial structure and diversity, and consolidate the sleep/wake cycle. There was no major change in any of the high-abundance bacterial phyla, but there was significant decrease in Deferribacteres and this was strongly correlated with longer non-rapid eye movement sleep [63].

The concentration and composition of the polyphenols in our diet may also potentially influence host circadian rhythms, albeit in peripheral tissues, by modulating the growth of gut commensals, which in turn generate bioactive SCFA or polyphenolic metabolites. For example, the polyphenol quercetin, ubiquitously found in plant foods, has a differential effect on the growth of gut commensals, with minimum inhibitory concentrations (MIC) being much lower for Ruminococcus gauvreauii, compared to Enterococcus caccae (MIC R. gauvreauii < MIC Bifidobacterium catenulatum < MIC E. caccae) [64]. While the latter two organisms produce lactate, the end product metabolite of Ruminococcus is butyrate, which has been shown to phase-advance hepatic clocks in mice (detailed in the SCFA section later) [65]. A decrease in the populations of Firmicutes (which includes both enterococci and ruminococci) compared to Bacteroidetes, results in an increased propionate/butyrate ratio in their metabolites, which was also observed with quercetin, at concentrations representative of a moderate consumption of a plant-based diet in an ex vivo simulation of the colon [66]. Thus polyphenols through their effects on the abundance and activity of gut bacteria may potentially influence the host circadian machinery. Furthermore, some polyphenols undergo microbial transformation to form metabolites, which may induce circadian entrainment. One such example is secoisolaricylresinol diglucoside (SDG), of which flaxseed is the richest source. SDG is minimally absorbed, and reaches the large intestine. SDG was shown to be metabolized by Firmicutes such as Eggerthella lenta and C. coccoides-E. rectale cluster to enterolactone $[67,68]$. A single dose of enterolactone $(10 \mathrm{mg} / \mathrm{kg}$ body weight $)$ was shown to influence canonical clock genes in $3 \mathrm{~h}$ in the murine uterus, by increasing the expression of Clock and decreasing that of Per3 [69].

Meal timing and the eating window are now emerging to be just as important as the composition of the diet in entraining microbiome rhythmicity. In a study by Zarrinpar et al. [17], the gut microbiome was studied in mice fed a high fat diet only between ZT13 to ZT21 (ZT12 = lights off) or ad libitum. Mice on ad libitum regular chow were included as controls. After eight weeks, only the ad libitum high fat fed mice were obese with glucose intolerance. Dark phase restricted feeding elicited at least some microbiota changes that were closer to the regular chow fed microbial profile, and reversed, albeit partly, the obesogenic microbial profile caused by ad libitum high fat feeding. Time-restricted feeding (TRF; ZT13-ZT21) restored the cyclical circadian rhythmicity and the relative abundance of Lactobacillus spp. in the animals on the high-fat diet, to resemblethe Lactobacillus profile of the regular chow mice. TRF also decreased the abundance of Lactococcus spp. compared to the ad libitum high fat diet, which showed increased Lactococcus spp. Both these species are presumed obesogenic. TRF also restored the abundance, but not the cyclical rhythms of Clostridia and Ruminococcaceae such as Oscillibacter, during the active phase comparable to that seen with regular chow [17]. Indeed, microbial rhythms, such as those generated by TRF, may have greater metabolic consequences for the host than microbial abundances. Similarly, in humans, the length of overnight fasting (which may be considered 
as a form of TRF) was found to be proportional to the faecal propionate, which is channeled towards gluconeogenesis in the liver $[12,28]$.

\section{Gut Microbiota as a Potential Pathway to Restore Circadian Rhythm and Metabolic Health}

Gut bacteria are increasingly recognized as being a critical organ within the human body, essential for development and maintenance of intestinal integrity and barrier, and optimal energy harvest. They play an important role in controlling the host's metabolism and immunity [70,71]. Thus it should not come as a surprise that gut microbiota and its metabolites may also potentially influence host circadian rhythms [65]. We discuss here the microbial metabolites that might influence body clocks with outcomes in body weight and metabolic homeostasis (outlined in Tables 2 and 3).

\subsection{Secondary Bile Acids}

Bile metabolism is an example of host and gut microbial activities, that are fixed to certain daily time points, as they co-ordinate metabolic homeostasis [72,73]. The liver secretes bile acids to facilitate the esterification and absorption of dietary fats and lipid soluble vitamins. The enterohepatic recycling of bile has a clear daily rhythm. Studies in mice demonstrate that the serum bile acids peak at the beginning and end of the dark phase. While most of the bile acids are resorbed by the liver from the distal ileum, some flow into the colon and undergo microbial metabolism, resulting in a serum peak of the secondary bile acids at the beginning of the dark phase $[74,75]$. This colonic microbial biotransformation includes deconjugation by bile salt hydrolases (bsh), followed by dehydroxylase and dehydrogenase activity, attributed to bacteria mostly from Firmicutes (Lachnospiraceae, Clostridiaceae, Erysepelotrichaceae, Ruminococcaceae, Lactobacillus), Bacteroidetes (Bacteroides), and Bifidobacterium [72,73]. Bsh-transformed E. coli colonization in both germ-free as well as conventionalized mice has confirmed the role of microbial deconjugation and biotransformation of bile acids in regulating hepatic and ileal clock genes (Per1/2), and clock controlled genes that regulate metabolism of lipid (PPAR $\gamma$, Angtpl4) and cholesterol (Abcg5/8) [76].

Bile acids also shape the gut microbial landscape by affecting the membrane integrity of bile-sensitive Gram negative bacteria, many of which are pathogenic or pro-inflammatory due to their lipopolysaccharide endotoxins [72], and Gram positive bacteria such as lactobacilli and bifidobacteria [77]. A high cholic acid diet in rats caused a decrease in bile-sensitive Bacteroides, with a concomitant increase in Firmicutes, especially Blautia (class Clostridia) and Allobaculum (Erysipelotrichi) [77]. Thus, stressors such as a high-fat diet which lead to an arrhythmia in bile metabolism may potentially affect the rhythms of the gut microbiome composition and function (such as $b s h)$, which in turn impact the rhythms of host metabolism, in this case, of lipids [77].

The increased levels of circulating bile acids in type 2 diabetic mice [78], indicates a much lower functional abundance of $b s h$ in diabetes compared to control, which was corroborated with a metadata analysis [73].

\subsection{Hydrogen Sulfide}

The dissimilatory sulfite reductase $(d s r \mathrm{AB})$, a low relative abundance microbial gene, is critical for the cycling of the sulfated compounds, such as the bile components and sulfated-mucins that reach the colon [14]. This $d s r A B$ is present predominantly in Deltaproteobacteria such as Desulfovibrio, Desulfotobacter, Desulfobulbus, and the taurine utilising Bilophila wadsworthia, causing a net increase in $\mathrm{H}_{2} \mathrm{~S}$ in the distal colon [13]. An increase in these Proteobacteria is prognostic of microbial dysbiosis. For example, the sulfate-reducing Desulfovibro piger has been shown to preferentially use up microbial lactate and competitively inhibit butyrate producers such as Eubacterium hallii and Anaerostipes caccae, that also require lactate [29]. The built up $\mathrm{H}_{2} \mathrm{~S}$ is a powerful inhibitor of microbial functions, such as production of butyrate, a major source of energy in the colon, but also inhibits host functions, such as mitochondrial cytochrome c oxidase involved in the oxidative phosphorylation, thereby decreasing the amount of energy available for cell survival [79]. $\mathrm{H}_{2} \mathrm{~S}$ has been shown to phase-delay Bmal1 expression 
in mice hepatic organoids [65]. An increased microbial $\mathrm{H}_{2} \mathrm{~S}$ (along with decreased butyrate) was observed along with suppressed substrate oxidation and elevated systemic glucose in high-fat fed mice [65]. Sulfate and taurine conjugates of bile and fatty acids, including sulfocholic acid, oxocholic acid sulfate, taurocholic acid sulfate, and cyprinol sulfate were found to be increased in faecal extracts of diabetic mice, indicating increased populations of intestinal sulfate-reducing bacteria in the diabetic mice [78].

\subsection{Short Chain Fatty Acids}

Gut bacteria break down digestion-resistant carbohydrates that reach the bowel to produce organic acids such as lactate and short SCFA metabolites such as acetate, propionate, and butyrate. Acetate and lactate are further utilized by secondary feeders to generate propionate and butyrate [12]. The acids not utilized in the colon enter the systemic circulation for absorption by peripheral tissues. The 4-carbon butyrate (more than the 3-carbon propionate or the 2-carbon acetate) plays a role in regulating plasma glucose by multiple mechanisms including activation of receptors that signal the secretion of satiety hormones, stimulation of insulin secretion, and suppression of pancreatic glucagon [6,80]. However, since acetate can also drive metabolism towards an obesogenic phenotype, as shown in a recent study with high-fat fed rats, it is important to have a full complement of gut bacteria to drive the carbohydrate fermentation to completion and enable the realization of microbiome-mediated metabolic benefits to the host $[10,81]$.

Treatment with either $5 \mathrm{mM}$ acetate or butyrate, was found to modulate the expression of the clock genes, Per 2 and Bmal1 in hepanoids that had been phase-synchronized with serum shock. Butyrate caused a significant change at the end of $8 \mathrm{~h}$ (Per2 decrease by 0.5 fold, and Bmal1 increase by 4-fold) [65]. Hepatic Bmal1 expression was suppressed and Per2 (and Cry1) increased in the dark phase for high-fat mice with guts colonized with specific pathogen-free microbiota. This effect on hepatic expression of clock genes was microbiota-mediated, and not observed when the gut was devoid of microbiota. The ex vivo experiments along with the in vivo observation confirm that microbiome, and its metabolites, at least partially explain the impact of five weeks of a high-fat diet on peripheral circadian rhythms in mice [65]. The same study also examined the effect of circulating butyrate on peripheral clock genes in mice at two different time points of the day. An intraperitoneal injection of butyrate $(1000 \mathrm{mg} / \mathrm{kg}$ body weight) at ZT14 as opposed to ZT2 for 5 days, was found to increase Per2:Bmal1 ratio (significantly in the liver, and approaching significance in the brain's mediobasal hypothalamus) [65]. This study clearly indicates the microbiota-circadian link, although a high amount of plant-based fiber needs to be consumed and metabolized to butyrate at one time point, to achieve the concentrations of butyrate used in this study. Application of a mixture of SCFAs and lactate, at a concentration that may be achieved in vivo $(100 \mu \mathrm{M})$, did not cause significant changes to Per2 rhythms in mouse embryonic fibroblasts. There was, however, a dose-dependent (10 $\mu \mathrm{M}$ to $1 \mathrm{mM}$ range) decrease in the amplitude of the first Per 2 peak, with significant change at $1 \mathrm{mM}$ [62]. The concentration or the proportion of the individual components of this acid mixture are not given; it is possible that one or more of these acids (e.g., butyrate) may not have achieved the critical concentration required to induce Per 2 entrainment. Irrespective, this effect is of significant interest given that trends of circadian entrainment emerge with diet and adjusting meal timings rather than pharmacological intervention.

Butyrate also potentially exerts an epigenetic control on circadian rhythms due to its ability to inhibit NAD ${ }^{+}$-dependent histone deacetylases such as sirtuin-1 (SIRT1) [82,83]. SIRT1 promotes the acetylation of BMAL1 associating with the CLOCK protein in the CLOCK:BMAL1 dimers [84]. SIRT1 thus plays a critical role in maintaining circadian rhythms and energy homeostasis via fat and glucose metabolism pathways, by promoting hepatic gluconeogenesis and fatty acid oxidation with effects on insulin sensitivity [85]. A note of caution though is that while butyrate and CoA individually act as histone deacetylase inhibitors, butyryl CoA acts an activator indicating that the effects of multiple derivatives of metabolites must be considered for their effects on histone deacetylases [86]. 
Table 2. Major microbiota-mediated mechanisms that influence host circadian and metabolic pathways *

\begin{tabular}{|c|c|c|}
\hline Microorganisms & Microbial Function & Interactions with Host Pathway \\
\hline $\begin{array}{l}\text { Firmicutes (Lachnospiraceae, Clostridiaceae, } \\
\text { Erysepelotrichaceae, Ruminococcaceae, Lactobacillus), } \\
\text { Bacteroidetes (Bacteroides), and Bifidobacterium [72,73]. }\end{array}$ & $\begin{array}{l}\text { Microbial bile salt hydrolases deconjugate bile } \\
\text { deoxycholic acid and lithocholic acid [76]. }\end{array}$ & $\begin{array}{l}\text { Microbial bile salt hydrolase associated with modulation of } \\
\text { canonical clock genes, genes related to lipid metabolism and } \\
\text { immune homeostasis [76]. }\end{array}$ \\
\hline $\begin{array}{c}\text { Desulfovibrio, Desulfotobacter, Desulfobulbus, } \\
\text { Bilophila wadsworthia [13]. }\end{array}$ & $\begin{array}{l}\text { Act on sulfated compounds to generate hydrogen } \\
\text { sulfide in the colon. }\end{array}$ & $\begin{array}{c}\text { Hydrogen sulfide phase-delays hepatic Bmal1 expression, } \\
\text { which is also associated with suppressed substrate oxidation } \\
\text { and elevated systemic glucose [65]. }\end{array}$ \\
\hline $\begin{array}{c}\text { Lachnospiraceae (Roseburia), Eubacteriaceae } \\
\text { (Eubacterium rectale), and Ruminococcaceae } \\
\text { (Ruminococcus bromii, Faecalibacterium prausnitzii) }[11,12]\end{array}$ & $\begin{array}{l}\text { Break down dietary fiber to generate butyrate in } \\
\text { the colon [58]. }\end{array}$ & $\begin{array}{l}\text { Butyrate is a key metabolic fuel for colonic epithelial cells } \\
\text { [11,12]; regulates plasma glucose by multiple mechanisms } \\
\text { including activation of receptors that signal the secretion of } \\
\text { satiety hormones, stimulation of insulin secretion and } \\
\text { suppression of pancreatic glucagon }[6,80] \text {; modulates } \\
\text { canonical clock genes in peripheral tissue [65]; acts as a } \\
\text { histone deacetylase inhibitor }[82,83] \text {. }\end{array}$ \\
\hline Clostridum sporogenes and Ruminococcus gnavus [87]. & $\begin{array}{l}\text { Generate precursors of biogenic amines such as } \\
\text { serotonin [87]. }\end{array}$ & $\begin{array}{c}\text { Bioamines such as serotonin play a role in intestinal motility } \\
\text { and secretory activity [88]. }\end{array}$ \\
\hline
\end{tabular}

${ }^{*}$ Microorganisms related to synthesis of vitamins elaborated in Table 3. 


\subsection{Vitamins}

Some B vitamins have been directly or indirectly linked with circadian rhythms and sleep patterns $[89,90]$. While vitamins are often diet-derived, about $40-65 \%$ of gut bacteria have the genetic capacity to synthesize vitamins that are not produced by the host $[11,91]$. This metabolic capacity, distributed across different phyla, is an example of how microbiota can affect metabolism and behavior of its larger multi-cellular hosts (Table 3). The biosynthesis of vitamin B12, a complex small molecule that is essential for the survival of both host and the microbiome, exemplifies the co-operative conundrum that the commensal community establish for their survival, irrespective of their value to the host. Thus Veillonellaceae and Alphaproteobacteria may share the metabolic burden of synthesis of B12, but are co-dependent on the Bacteroides thetaiotamicron that navigate through the mucosal barrier to bind the dietary corrinoids (vitamin B12 precursors) and make them accessible to the microbiota for B12 synthesis [92].

Table 3. Microbially synthesized vitamins and their physiological effects through circadiancontrolled mechanisms.

\begin{tabular}{ccc}
\hline Vitamin & $\begin{array}{c}\text { Physiological Effects Through Circadian } \\
\text { Controlled Mechanisms }\end{array}$ & $\begin{array}{c}\text { Examples of Microorganisms } \\
\text { That Synthesize the Vitamin }\end{array}$ \\
\hline B1, thiamine & Core body temperature, rat study [93] & $\begin{array}{c}\text { Streptococcus thermophilus ST5, } \\
\text { Lactobacillus helveticus R0052, } \\
\text { Bifidobacterium longum R0175 [94] }\end{array}$ \\
\hline B2, riboflavin & $\begin{array}{c}\text { Affects metabolism by } \\
\text { influencingcryptochrome 2 stability [95] }\end{array}$ & Bacillus subtilis, Escherichia coli [94] \\
\hline B3, niacin & $\begin{array}{c}\text { Lowered blood B3 associated with } \\
\text { decreased duration of deep sleep in } \\
\text { Parkinson's disease [96] }\end{array}$ & E. coli [91] \\
\hline B9, folic acid & $\begin{array}{c}\text { Important for brain function by regulating } \\
\text { brain clock genes [97]; lowered serum B9 } \\
\text { associated with sleep disturbance [90] }\end{array}$ & Bifidobacterium spp., \\
Lactobacillus spp. [94]
\end{tabular}

\subsection{Biogenic Amines}

Sleep deprivation was found to cause a profound effect on the plasma metabolome, with an increase in biogenic amines or their precursors [99], which may be linked to increases in Firmicutes observed in sleep deprivation [43,45]. Dietary tryptophan is converted to serotonin in the host, and some of this transformation is attributable to microbial pathways given that germ-free mice show a 2.8-fold decrease in circulating serotonin [100]. Firmicutes such as Clostridum sporogenes and Ruminococcus gnavus, have been shown to harbor the tryptophan decarboxylase gene, homologs of which have been detected in $9-17 \%$ of healthy human gut metagenome [87]. Spore-forming clostridia further stimulate enterochromaffin cells to convert the end product tryptamine to the neurotransmitter serotonin. More than $90 \%$ of the body's serotonin is gut-derived, and plays a role in peripheral functions including intestinal motility and secretory activity [88]. The microbial colonization of the intestine is also implicated in regulating brain serotoninergic pathways [101]. This in turn may influence the hippocampal concentrations of serotonin, a neurochemical that shows diurnal variations, and is implicated in promoting sleep and regulating hypothalamic pathways of glucose homeostasis [102].

A serotonin-derived bioamine, melatonin is implicated in regulating sleep/wake functions when synthesized in the brain. Gut-derived melatonin has been suggested to play a role in regulating insulin sensitivity and mitochondrial oxidation [103]. New studies indicate bidirectional associations between representatives of gut bacteria and host melatonin concentrations [104,105]. Intake of VSL\#3 probiotics were also shown to improve sleep and intestinal symptoms in irritable bowel syndrome, which was associated with an increase in melatonin in early morning saliva samples [104]. On the other hand, 
gut bacteria are also responsive to bioamines in terms of their behavior and responses. In vitro studies indicated that pure cultures of Enterobacter aerogenes increase their swarming motility in the presence of melatonin [105]. This is particularly interesting given that E. aerogenes are opportunistic pathogens and produce pro-inflammatory endotoxins, and their presence significantly correlates with obesity [16]. It is thus possible that microbiota interactions with sleep-inducing biogenic amines potentially influence the circadian-metabolic axis.

\subsection{Probiotics}

Gut microbial dysbiosis and enteric infections are common factors in irritable bowel syndrome, and disrupted sleep is often associated as a co-morbidity [106]. Treatment with VSL\#3, a combination of probiotic bacteria including Bifidobacterium (B. longum, B. infantis, and B. breve); Lactobacillus (L. acidophilus, L. casei, L. delbrueckii ssp. Bulgaricus, and L. plantarum), and Streptococcus salivarius ssp. thermophilus was found to improve sleep and abdominal pain in irritable bowel syndrome [104]. Although probiotic bacteria are exogenously administered and are often transient in their gut colonization [107], it is promising that close representatives of endogenous gut microbiota are implicated in sleep as well as gut health. It indicates the plausibility of prebiotic strategies to enhance endogenous beneficial organisms and restore health.

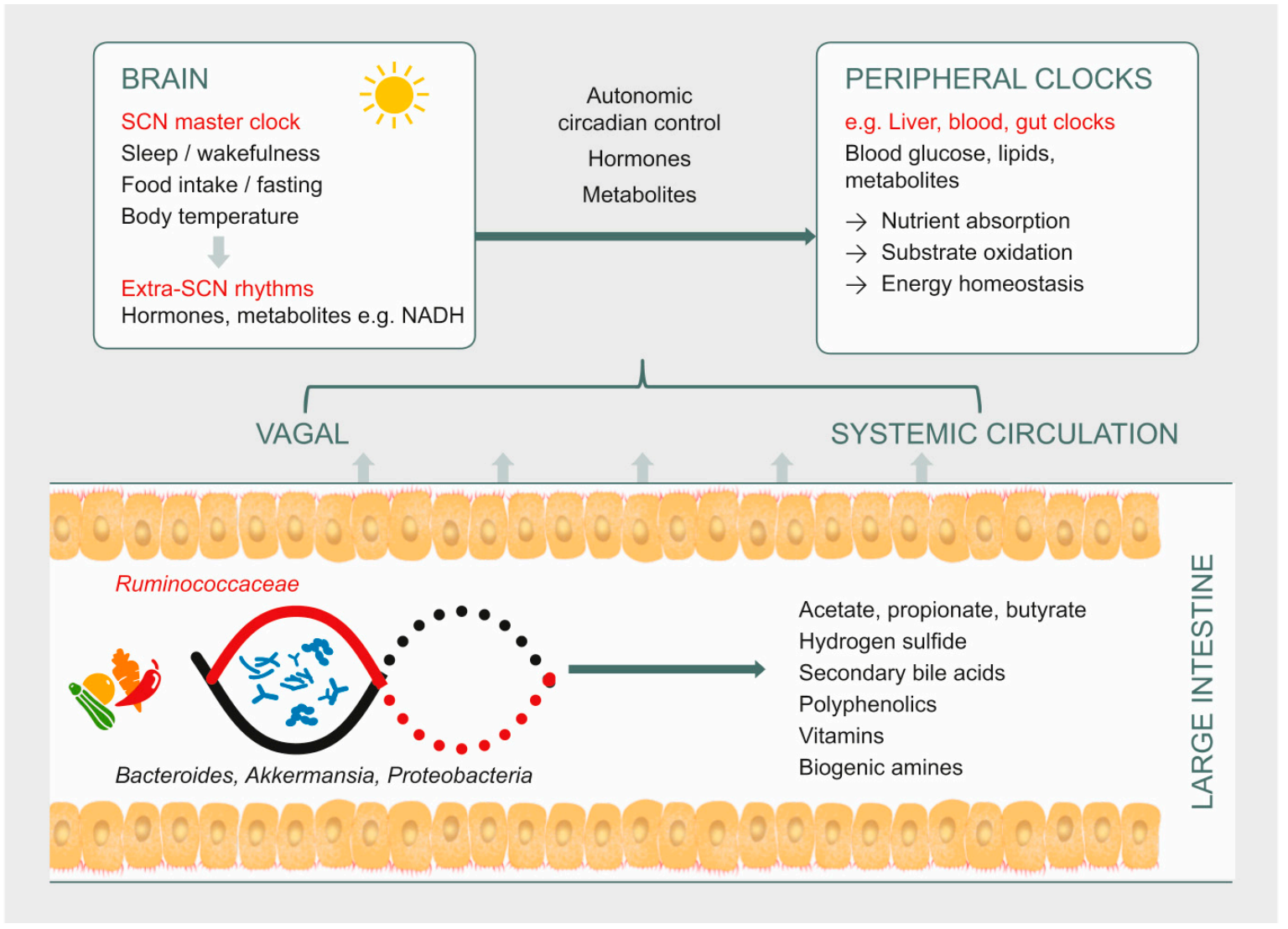

Figure 2. Potential mechanism of gut microbiota interactions in the circadian-metabolic axis. Host behavior, sleep, and diet control gut bacteria, which in turn show changes in terms of microbial composition and functional genome in a rhythmic manner. Circadian rhythms may be affected by microbial metabolites such as butyrate, secondary bile acids, and microbially synthesized vitamins, and potentially disrupted by hydrogen sulphide. The immediate effects on energy resources for colonic epithelial cells, and peripheral effects on substrate oxidation via systemic circulation potentially impact energy homeostasis. 
In summary, host microbial rhythms may be considered a composite of peaks by the host-glycan foragers (primarily Bacteroidetes, but also Verrucomicrobia, and the opportunistic Enterobacteriaceae) anti-phase to thediet-driven Firmicutes peaks. Disruptions in sleep, diet, and eating patterns influence the diurnal dynamics of gut microbiome structure and activity. We propose a microbially-mediated mechanism of circadian disruption that involves alterations in the distinct time-of-day microbial signatures. If physiological adaptations to circadian disruption are not accompanied by gut microbial adaptation to time-of-day patterns, there may be metabolic consequences to the host in terms of the efficiency of energy extraction and utilization (Figure 2). For example, a decrease in bile metabolizing species and the consequent lowered bsh, may contribute to an increase in bile that in turn affects the rhythms in many bile-sensitive commensals while promoting sulfate reducers or pathobionts. The built up $\mathrm{H}_{2} \mathrm{~S}$ caused by the bloom of sulfate reducers (increase in $d s r A B$ ) has been shown to strongly inhibit mitochondrial oxidation processes, and also phase-delay peripheral clocks. Sulfate-reducers also competitively inhibit the growth of butyrate producers, thus decreasing butyrate-a major energy source for colonic epithelium-potentially comprising epithelial integrity. The resulting dysbiosistriggers pro-inflammatory pathways leading to metabolic dysfunction-the hallmark of which is glucose intolerance.

\section{Conclusions}

This review examines current evidence on the interdependency of host circadian systems and gut microbial ecology, and the consequences of this interaction for the host metabolism. There are many lifestyle features in the modern society that may contribute to the current epidemic of metabolic health problems such as obesity, type 2 diabetes, and metabolic syndrome. These features include, high fat/high sugar convenience foods and poor sleep due to modern-day stressors such as long working hours, multi-time-zone travel, and little exposure to daylight. All these lifestyle factors not only impact and disturb the circadian timing system, but also influence the make-up of our gut microbiome. The timing of eating a meal and the type of food may also affect circadian clocks, not just by host mediated cues but by virtue of the microbiota that it modulates. Both good sleep and a healthy diet, especially when time-of-day-appropriate, may thus be essential for maintaining metabolic homeostasis.

The last five years have shown that the gut's microbial residents also show a circadian rhythm in terms of their composition and function, and even their ability to invade and colonize the gut. Current evidence indicates an increase in total gut bacterial mass and Firmicutes, in response to the food ingested during the waking/eating phase, and an increase in Bacteroidetes, Proteobacteria and Verrucomicrobiaduring the sleeping/fasting phase. There is also evidence of diurnal variation in the microbial metabolites such as butyrate and $\mathrm{H}_{2} \mathrm{~S}$, which in turn affects the host's circadian rhythm and metabolism. For example, pathobionts such as Desulfovibrio and the bile-tolerant Bilophila increase during the day and produce $\mathrm{H}_{2} \mathrm{~S}$.

Manipulating the microbiome might therefore be a promising strategy to restore the host's circadian rhythm and metabolic homeostasis. Plant foods are a rich source of fiber and polyphenols, the undigested components of which reach the colon to generate beneficial metabolites including SCFAs and polyphenolic bioactives, which in turn not only maintain colonic health and protect against pathogens, but also might help resynchronize circadian rhythms. For example, one may expect increases in Ruminococcaceae and Lachnospiraceae with a high fiber diet, and subsequent generation of butyrate to support the energy requirements of the intestinal cells during the day, and provide extra entrainment to the peripheral organs such as the liver and potentially brain.

We also discussed the contributing pathways and gut microbiota-based mechanisms that may rescue the host from the pathological manifestations of circadian disruption. These include microbial generation of bioactive SCFAs, polyphenolic metabolites, vitamins, and bioamines. This is particularly valuable because diet offers natural therapeutic strategies to modulate our microbiota. We acknowledge that in isolation, none of the above factors solve the metabolic issues arising from chronic circadian disruption, but given that modern lifestyles are here to stay, dietary manipulations are probably 
something that consumers are willing to try. Because many components in food can alter gut microbial composition and functions, it is possible that manipulating the quality, quantity, or timing of food, may manipulate our gut microbiota and ultimately influence and mitigate some of the metabolic consequences of modern lifestyle-associated issues such as disrupted sleep and disorganized circadian rhythms.

Author Contributions: All authors have approved the final version of the manuscript and agree to be accountable for all aspects of the work. All persons designated as authors qualify for authorship, and all those who qualify for authorship are listed.

Funding: Core funding from The New Zealand Institute for Plant \& Food Research Limited awarded to Shanthi Parkar through Discovery Science programme "Resetting clock genes"; contract \# P/225005/01.

Acknowledgments: We acknowledge the assistance of Andrea Leonard-Jones with the graphics.

Conflicts of Interest: The authors report no conflicts of interest.

\section{References}

1. Bass, J.; Takahashi, J.S. Circadian integration of metabolism and energetics. Science 2010, 330, 1349-1354. [CrossRef] [PubMed]

2. Oosterman, J.E.; Kalsbeek, A.; la Fleur, S.E.; Belsham, D.D. Impact of nutrients on circadian rhythmicity. Am. J. Physiol. Regul. Integr. Comp. Physiol. 2015, 308, R337-R350. [CrossRef] [PubMed]

3. Depner, C.M.; Stothard, E.R.; Wright, K.P., Jr. Metabolic consequences of sleep and circadian disorders. Curr. Diabetes Rep. 2014, 14, 507. [CrossRef]

4. Shi, S.Q.; Ansari, T.S.; McGuinness, O.P.; Wasserman, D.H.; Johnson, C.H. Circadian disruption leads to insulin resistance and obesity. Curr. Biol. 2013, 23, 372-381. [CrossRef]

5. Turnbaugh, P.J.; Hamady, M.; Yatsunenko, T.; Cantarel, B.L.; Duncan, A.; Ley, R.E.; Sogin, M.L.; Jones, W.J;; Roe, B.A.; Affourtit, J.P.; et al. A core gut microbiome in obese and lean twins. Nature 2009, 457, 480-485. [CrossRef] [PubMed]

6. Remely, M.; Aumueller, E.; Merold, C.; Dworzak, S.; Hippe, B.; Zanner, J.; Pointner, A.; Brath, H.; Haslberger, A.G. Effects of short chain fatty acid producing bacteria on epigenetic regulation of FFAR3 in type 2 diabetes and obesity. Gene 2014, 537, 85-92. [CrossRef] [PubMed]

7. Bhute, S.S.; Suryavanshi, M.V.; Joshi, S.M.; Yajnik, C.S.; Shouche, Y.S.; Ghaskadbi, S.S. Gut microbial diversity assessment of Indian type-2-diabetics reveals alterations in eubacteria, archaea, and eukaryotes. Front. Microbiol. 2017, 8, A214. [CrossRef] [PubMed]

8. Hippe, B.; Remely, M.; Aumueller, E.; Pointner, A.; Magnet, U.; Haslberger, A. Faecalibacterium prausnitzii phylotypes in type two diabetic, obese, and lean control subjects. Benef. Microbes 2016, 7, 511-517. [CrossRef] [PubMed]

9. Hussain, M.M.; Pan, X. Circadian regulators of intestinal lipid absorption. J. Lipid Res. 2015, 56, 761-770. [CrossRef] [PubMed]

10. Turnbaugh, P.J.; Ridaura, V.K.; Faith, J.J.; Rey, F.E.; Knight, R.; Gordon, J.I. The effect of diet on the human gut microbiome: A metagenomic analysis in humanized gnotobiotic mice. Sci. Transl. Med. 2009, 1, 6ra14. [CrossRef] [PubMed]

11. Arumugam, M.; Raes, J.; Pelletier, E.; Le Paslier, D.; Yamada, T.; Mende, D.R.; Fernandes, G.R.; Tap, J.; Bruls, T.; Batto, J.M.; et al. Enterotypes of the human gut microbiome. Nature 2011, 473, 174-180. [CrossRef] [PubMed]

12. Louis, P.; Scott, K.P.; Duncan, S.H.; Flint, H.J. Understanding the effects of diet on bacterial metabolism in the large intestine. J. Appl. Microbiol. 2007, 102, 1197-1208. [CrossRef] [PubMed]

13. Carbonero, F.; Benefiel, A.; Alizadeh-Ghamsari, A.; Gaskins, H.R. Microbial pathways in colonic sulfur metabolism and links with health and disease. Front. Physiol. 2012, 3, 448. [CrossRef]

14. Human Microbiome Project, C. Structure, function and diversity of the healthy human microbiome. Nature 2012, 486, 207-214. [CrossRef] [PubMed] 
15. Dao, M.C.; Everard, A.; Aron-Wisnewsky, J.; Sokolovska, N.; Prifti, E.; Verger, E.O.; Kayser, B.D.; Levenez, F.; Chilloux, J.; Hoyles, L. Akkermansia muciniphila and improved metabolic health during a dietary intervention in obesity: Relationship with gut microbiome richness and ecology. Gut 2016, 65, 426-436. [CrossRef] [PubMed]

16. Verdam, F.J.; Fuentes, S.; de Jonge, C.; Zoetendal, E.G.; Erbil, R.; Greve, J.W.; Buurman, W.A.; de Vos, W.M.; Rensen, S.S. Human intestinal microbiota composition is associated with local and systemic inflammation in obesity. Obesity 2013, 21, E607-E615. [CrossRef]

17. Zarrinpar, A.; Chaix, A.; Yooseph, S.; Panda, S. Diet and feeding pattern affect the diurnal dynamics of the gut microbiome. Cell Metab. 2014, 20, 1006-1017. [CrossRef]

18. Zhang, R.; Lahens, N.F.; Ballance, H.I.; Hughes, M.E.; Hogenesch, J.B. A circadian gene expression atlas in mammals: Implications for biology and medicine. Proc. Natl. Acad. Sci. USA 2014, 111, 16219-16224. [CrossRef]

19. Marcobal, A.; Southwick, A.M.; Earle, K.A.; Sonnenburg, J.L. A refined palate: Bacterial consumption of host glycans in the gut. Glycobiology 2013, 23, 1038-1046. [CrossRef]

20. Thaiss, C.A.; Zeevi, D.; Levy, M.; Zilberman-Schapira, G.; Suez, J.; Tengeler, A.C.; Abramson, L.; Katz, M.N.; Korem, T.; Zmora, N.; et al. Transkingdom control of microbiota diurnal oscillations promotes metabolic homeostasis. Cell 2014, 159, 514-529. [CrossRef]

21. Liang, X.; Bushman, F.D.; FitzGerald, G.A. Rhythmicity of the intestinal microbiota is regulated by gender and the host circadian clock. Proc. Natl. Acad. Sci. USA 2015, 112, 10479-10484. [CrossRef] [PubMed]

22. Thaiss, C.A.; Levy, M.; Korem, T.; Dohnalová, L.; Shapiro, H.; Jaitin, D.A.; David, E.; Winter, D.R.; Gury-BenAri, M.; Tatirovsky, E.; et al. Microbiota diurnal rhythmicity programs host transcriptome oscillations. Cell 2016, 167, 1495-1510. [CrossRef] [PubMed]

23. Voigt, R.M.; Summa, K.C.; Forsyth, C.B.; Green, S.J.; Engen, P.; Naqib, A.; Vitaterna, M.H.; Turek, F.W.; Keshavarzian, A. The circadian clock mutation promotes intestinal dysbiosis. Alcohol.-Clin. Exp. Res. 2016, 40, 335-347. [CrossRef] [PubMed]

24. Bellet, M.M.; Deriu, E.; Liu, J.Z.; Grimaldi, B.; Blaschitz, C.; Zeller, M.; Edwards, R.A.; Sahar, S.; Dandekar, S.; Baldi, P.; et al. Circadian clock regulates the host response to Salmonella. Proc. Natl. Acad. Sci. USA 2013, 110, 9897-9902. [CrossRef] [PubMed]

25. Marianelli, C.; Cifani, N.; Pasquali, P. Evaluation of antimicrobial activity of probiotic bacteria against Salmonella enterica subsp. enterica serovar typhimurium 1344 in a common medium under different environmental conditions. Res. Microbiol. 2010, 161, 673-680.

26. Deaver, J.A.; Eum, S.Y.; Toborek, M. Circadian disruption changes gut microbiome taxa and functional gene composition. Front. Microbiol. 2018, 9, 737. [CrossRef] [PubMed]

27. Wu, G.; Tang, W.; He, Y.; Hu, J.; Gong, S.; He, Z.; Wei, G.; Lv, L.; Jiang, Y.; Zhou, H.; et al. Light exposure influences the diurnal oscillation of gut microbiota in mice. Biochem. Biophys. Res. Commun. 2018, 501, 16-23. [CrossRef]

28. Kaczmarek, J.L.; Musaad, S.M.; Holscher, H.D. Time of day and eating behaviors are associated with the composition and function of the human gastrointestinal microbiota. Am. J. Clin. Nutr. 2017, 106, 1220-1231. [CrossRef]

29. Marquet, P.; Duncan, S.H.; Chassard, C.; Bernalier-Donadille, A.; Flint, H.J. Lactate has the potential to promote hydrogen sulphide formation in the human colon. FEMS Microbiol. Lett. 2009, 299, 128-134. [CrossRef]

30. Ndiaye, M.A.; Nihal, M.; Wood, G.S.; Ahmad, N. Skin, reactive oxygen species, and circadian clocks. Antioxid. Redox Signal. 2014, 20, 2982-2996. [CrossRef]

31. Gangloff, A.; Bergeron, J.; Lemieux, I.; Després, J.-P. Changes in circulating vitamin D levels with loss of adipose tissue. Curr. Opin. Clin. Nutr. Metab. Care 2016, 19, 464-470. [CrossRef] [PubMed]

32. Su, D.; Nie, Y.; Zhu, A.; Chen, Z.; Wu, P.; Zhang, L.; Luo, M.; Sun, Q.; Cai, L.; Lai, Y.; et al. Vitamin D signaling through induction of Paneth cell defensins maintains gut microbiota and improves metabolic disorders and hepatic steatosis in animal models. Front. Physiol. 2016, 7, 498. [CrossRef]

33. Assa, A.; Vong, L.; Pinnell, L.J.; Rautava, J.; Avitzur, N.; Johnson-Henry, K.C.; Sherman, P.M. Vitamin D deficiency predisposes to adherent-invasive Escherichia coli-induced barrier dysfunction and experimental colonic injury. Inflamm. Bowel Dis. 2015, 21, 297-306. [CrossRef] 
34. Chen, S.W.; Wang, P.Y.; Zhu, J.; Chen, G.W.; Zhang, J.L.; Chen, Z.Y.; Zuo, S.; Liu, Y.C.; Pan, Y.S. Protective effect of 1,25-dihydroxyvitamin D3 on lipopolysaccharide-induced intestinal epithelial tight junction injury in Caco-2 cell monolayers. Inflammation 2015, 38, 375-383. [CrossRef]

35. Bashir, M.; Prietl, B.; Tauschmann, M.; Mautner, S.I.; Kump, P.K.; Treiber, G.; Wurm, P.; Gorkiewicz, G.; Hogenauer, C.; Pieber, T.R. Effects of high doses of vitamin D-3 on mucosa-associated gut microbiome vary between regions of the human gastrointestinal tract. Eur. J. Nutr. 2016, 55, 1479-1489. [CrossRef]

36. Archer, S.N.; Oster, H. How sleep and wakefulness influence circadian rhythmicity: Effects of insufficient and mistimed sleep on the animal and human transcriptome. J. Sleep Res. 2015, 24, 476-493. [CrossRef] [PubMed]

37. Brown, R.; Price, R.J.; King, M.G.; Husband, A.J. Are antibiotic effects on sleep behavior in the rat due to modulation of gut bacteria? Physiol. Behav. 1990, 48, 561-565. [CrossRef]

38. Nonaka, K.; Nakazawa, Y.; Kotorii, T. Effects of antibiotics, minocycline and ampicillin, on human sleep. Brain Res. 1983, 288, 253-259. [CrossRef]

39. Brundula, V.; Rewcastle, N.B.; Metz, L.M.; Bernard, C.C.; Yong, V.W. Targeting Leukocyte MMPs and Transmigration: Minocycline as a Potential Therapy for Multiple Sclerosis. Brain 2002, 125, 1297-1308. [CrossRef] [PubMed]

40. Jackson, M.L.; Butt, H.; Ball, M.; Lewis, D.P.; Bruck, D. Sleep quality and the treatment of intestinal microbiota imbalance in Chronic Fatigue Syndrome: A pilot study. Sleep Sci. 2015, 8, 124-133. [CrossRef] [PubMed]

41. Quigley, E.M.M.; Quera, R. Small Intestinal Bacterial Overgrowth: Roles of Antibiotics, Prebiotics, and Probiotics. Gastroenterology 2006, 130, S78-S90. [CrossRef] [PubMed]

42. Weinstock, L.B.; Walters, A.S.; Paueksakon, P. Restless legs syndrome-Theoretical roles of inflammatory and immune mechanisms. Sleep Med. Rev. 2012, 16, 341-354. [CrossRef] [PubMed]

43. Benedict, C.; Vogel, H.; Jonas, W.; Woting, A.; Blaut, M.; Schurmann, A.; Cedernaes, J. Gut microbiota and glucometabolic alterations in response to recurrent partial sleep deprivation in normal-weight young individuals. Mol. Metab. 2016, 5, 1175-1186. [CrossRef] [PubMed]

44. Zhang, S.L.; Bai, L.; Goel, N.; Bailey, A.; Jang, C.J.; Bushman, F.D.; Meerlo, P.; Dinges, D.F.; Sehgal, A. Human and rat gut microbiome composition is maintained following sleep restriction. Proc. Natl. Acad. Sci. USA 2017, 114, E1564-E1571. [CrossRef] [PubMed]

45. Poroyko, V.A.; Carreras, A.; Khalyfa, A.; Khalyfa, A.A.; Leone, V.; Peris, E.; Almendros, I.; Gileles-Hillel, A.; Qiao, Z.; Hubert, N.; et al. Chronic sleep disruption alters gut microbiota, induces systemic and adipose tissue inflammation and insulin resistance in mice. Sci. Rep. 2016, 6, 35405. [CrossRef] [PubMed]

46. Giskeodegard, G.F.; Davies, S.K.; Revell, V.L.; Keun, H.; Skene, D.J. Diurnal rhythms in the human urine metabolome during sleep and total sleep deprivation. Sci. Rep. 2015, 5, 14843. [CrossRef] [PubMed]

47. Voigt, R.M.; Forsyth, C.B.; Green, S.J.; Mutlu, E.; Engen, P.; Vitaterna, M.H.; Turek, F.W.; Keshavarzian, A. Circadian disorganization alters intestinal microbiota. PLoS ONE 2014, 9, e97500. [CrossRef] [PubMed]

48. Bishehsari, F.; Saadalla, A.; Khazaie, K.; Engen, P.A.; Voigt, R.M.; Shetuni, B.B.; Forsyth, C.; Shaikh, M.; Vitaterna, M.H.; Turek, F.; et al. Light/dark shifting promotes alcohol-induced colon carcinogenesis: Possible role of intestinal inflammatory milieu and microbiota. Int. J. Mol. Sci. 2016, 17, 2017. [CrossRef]

49. Bobinski, R.; Michalik, A. Evaluation of early jet lag symptoms by passengers crossing 7 time zones. In Transport System Telematics; Mikulski, J., Ed.; Springer: Katowice-Ustron, Poland, 2010; Volume 104, pp. 356-363.

50. Roenneberg, T.; Allebrandt, K.V.; Merrow, M.; Vetter, C. Social jetlag and obesity. Curr. Biol. 2012, 22, $939-943$. [CrossRef] [PubMed]

51. Parsons, M.J.; Moffitt, T.E.; Gregory, A.M.; Goldman-Mellor, S.; Nolan, P.M.; Poulton, R.; Caspi, A. Social jetlag, obesity and metabolic disorder: Investigation in a cohort study. Int. J. Obes. 2015, 39, 842-848. [CrossRef] [PubMed]

52. Reynolds, A.C.; Paterson, J.L.; Ferguson, S.A.; Stanley, D.; Wright, K.P., Jr.; Dawson, D. The shift work and health research agenda: Considering changes in gut microbiota as a pathway linking shift work, sleep loss and circadian misalignment, and metabolic disease. Sleep Med. Rev. 2017, 34, 3-9. [CrossRef] [PubMed]

53. Stenvers, D.J.; Jonkers, C.F.; Fliers, E.; Bisschop, P.H.; Kalsbeek, A. Nutrition and the circadian timing system. Prog. Brain Res. 2012, 199, 359-376. [PubMed]

54. Dallmann, R.; Viola, A.U.; Tarokh, L.; Cajochen, C.; Brown, S.A. The human circadian metabolome. Proc. Natl. Acad. Sci. USA 2012, 109, 2625-2629. [CrossRef] 
55. Kohsaka, A.; Laposky, A.D.; Ramsey, K.M.; Estrada, C.; Joshu, C.; Kobayashi, Y.; Turek, F.W.; Bass, J. High-fat diet disrupts behavioral and molecular circadian rhythms in mice. Cell Metab. 2007, 6, 414-421. [CrossRef] [PubMed]

56. Shankar, V.; Gouda, M.; Moncivaiz, J.; Gordon, A.; Reo, N.V.; Hussein, L.; Paliy, O. Differences in gut metabolites and microbial composition and functions between Egyptian and U.S. children are consistent with their diets. mSystems 2017, 2, e00169-16. [CrossRef] [PubMed]

57. Jumpertz, R.; Duc Son, L.; Turnbaugh, P.J.; Trinidad, C.; Bogardus, C.; Gordon, J.I.; Krakoff, J. Energy-balance studies reveal associations between gut microbes, caloric load, and nutrient absorption in humans. Am. J. Clin. Nutr. 2011, 94, 58-65. [CrossRef]

58. David, L.A.; Maurice, C.F.; Carmody, R.N.; Gootenberg, D.B.; Button, J.E.; Wolfe, B.E. Diet rapidly and reproducibly alters the human gut microbiome. Nature 2014, 505, 559. [CrossRef]

59. Walker, A.W.; Ince, J.; Duncan, S.H.; Webster, L.M.; Holtrop, G.; Ze, X.; Brown, D.; Stares, M.D.; Scott, P.; Bergerat, A.; et al. Dominant and diet-responsive groups of bacteria within the human colonic microbiota. ISME J. 2011, 5, 220-230. [CrossRef]

60. Tuohy, K.M.; Conterno, L.; Gasperotti, M.; Viola, R. Up-regulating the human intestinal microbiome using whole plant foods, polyphenols, and/or fiber. J. Agric. Food Chem. 2012, 60, 8776-8782. [CrossRef]

61. Parkar, S.G.; Blatchford, P.A.; Kim, C.C.; Rosendale, D.I.; Ansell, J. New and tailored prebiotics: Established applications. In Probiotics and Prebiotics: Current Research and Future Trends; Venema, K., Ed.; Caister Academic Press: Poole, UK, 2015; pp. 289-314.

62. Tahara, Y.; Yamazaki, M.; Sukigara, H.; Motohashi, H.; Sasaki, H.; Miyakawa, H.; Haraguchi, A.; Ikeda, Y.; Fukuda, S.; Shibata, S. Gut microbiota-derived short chain fatty acids induce circadian clock entrainment in mouse peripheral tissue. Sci. Rep. 2018, 8, 1395. [CrossRef]

63. Thompson, R.S.; Roller, R.; Mika, A.; Greenwood, B.N.; Knight, R.; Chichlowski, M.; Berg, B.M.; Fleshner, M. Dietary prebiotics and bioactive milk fractions improve nrem sleep, enhance rem sleep rebound and attenuate the stress-induced decrease in diurnal temperature and gut microbial alpha diversity. Front. Behav. Neurosci. 2017, 10, 240. [CrossRef] [PubMed]

64. Firrman, J.; Liu, L.; Zhang, L.; Arango Argoty, G.; Wang, M.; Tomasula, P.; Kobori, M.; Pontious, S.; Xiao, W. The effect of quercetin on genetic expression of the commensal gut microbes Bifidobacterium catenulatum, Enterococcus caccae and Ruminococcus gauvreauii. Anaerobe 2016, 42, 130-141. [CrossRef]

65. Leone, V.; Gibbons, S.M.; Martinez, K.; Hutchison, A.L.; Huang, E.Y.; Cham, C.M.; Pierre, J.F.; Heneghan, A.F.; Nadimpalli, A.; Hubert, N.; et al. Effects of diurnal variation of gut microbes and high-fat feeding on host circadian clock function and metabolism. Cell Host Microbe 2015, 17, 681-689. [CrossRef] [PubMed]

66. Parkar, S.G.; Trower, T.M.; Stevenson, D.E. Fecal microbial metabolism of polyphenols and its effects on human gut microbiota. Anaerobe 2013, 23, 12-19. [CrossRef]

67. Eeckhaut, E.; Struijs, K.; Possemiers, S.; Vincken, J.P.; De Keukeleire, D.; Verstraete, W. Metabolism of the lignan macromolecule into enterolignans in the gastrointestinal lumen as determined in the simulator of the human intestinal microbial ecosystem. J. Agric. Food Chem. 2008, 56, 4806-4812. [CrossRef] [PubMed]

68. Clavel, T.; Henderson, G.; Alpert, C.A.; Philippe, C.; Rigottier-Gois, L.; Dore, J.; Blaut, M. Intestinal bacterial communities that produce active estrogen-like compounds enterodiol and enterolactone in humans. Appl. Environ. Microbiol. 2005, 71, 6077-6085. [CrossRef]

69. Damdimopoulou, P.; Nurmi, T.; Salminen, A.; Damdimopoulos, A.E.; Kotka, M.; van der Saag, P.; Strauss, L.; Poutanen, M.; Pongratz, I.; Makela, S. A single dose of enterolactone activates estrogen signaling and regulates expression of circadian clock genes in mice. J. Nutr. 2011, 141, 1583-1589. [CrossRef] [PubMed]

70. Chilloux, J.; Neves, A.L.; Boulange, C.L.; Dumas, M.E. The microbial-mammalian metabolic axis: A critical symbiotic relationship. Curr. Opin. Clin. Nutr. Metab. Care 2016, 19, 250-256. [CrossRef] [PubMed]

71. Bass, J. Circadian topology of metabolism. Nature 2012, 491, 348-356. [CrossRef]

72. Fiorucci, S.; Distrutti, E. Bile acid-activated receptors, intestinal microbiota, and the treatment of metabolic disorders. Trends Mol. Med. 2015, 21, 702-714. [CrossRef]

73. Labbe, A.; Ganopolsky, J.G.; Martoni, C.J.; Prakash, S.; Jones, M.L. Bacterial bile metabolising gene abundance in Crohn's, ulcerative colitis and type 2 diabetes metagenomes. PLoS ONE 2014, 9, e115175. [CrossRef] [PubMed] 
74. Eggink, H.M.; Oosterman, J.E.; de Goede, P.; de Vries, E.M.; Foppen, E.; Koehorst, M.; Groen, A.K.; Boelen, A.; Romijn, J.A.; la Fleur, S.E.; et al. Complex interaction between circadian rhythm and diet on bile acid homeostasis in male rats. Chronobiol. Int. 2017, 34, 1339-1353. [CrossRef] [PubMed]

75. Zhang, Y.K.J.; Guo, G.L.; Klaassen, C.D. Diurnal variations of mouse plasma and hepatic bile acid concentrations as well as expression of biosynthetic enzymes and transporters. PLOS ONE 2011, 6, e16683. [CrossRef]

76. Joyce, S.A.; MacSharry, J.; Casey, P.G.; Kinsella, M.; Murphy, E.F.; Shanahan, F.; Hill, C.; Gahan, C.G.M. Regulation of host weight gain and lipid metabolism by bacterial bile acid modification in the gut. Proc. Natl. Acad. Sci. USA 2014, 111, 7421-7426. [CrossRef] [PubMed]

77. Yokota, A.; Fukiya, S.; Islam, K.B.M.S.; Ooka, T.; Ogura, Y.; Hayashi, T.; Hagio, M.; Ishizuka, S. Is bile acid a determinant of the gut microbiota on a high-fat diet? Gut Microbes 2012, 3, 455-459. [CrossRef] [PubMed]

78. Walker, A.; Lucio, M.; Pfitzner, B.; Scheerer, M.F.; Neschen, S.; de Angelis, M.H.; Hartmann, A.; Schmitt-Kopplin, P. Importance of sulfur-containing metabolites in discriminating fecal extracts between normal and type-2 diabetic mice. J. Proteome Res. 2014, 13, 4220-4231. [CrossRef]

79. Nicholls, P.; Marshall, D.C.; Cooper, C.E.; Wilson, M.T. Sulfide inhibition of and metabolism by cytochrome c oxidase. Biochem. Soc. Trans. 2013, 41, 1312-1316. [CrossRef] [PubMed]

80. Frost, G.; Cai, Z.; Raven, M.; Otway, D.T.; Mushtaq, R.; Johnston, J.D. Effect of short chain fatty acids on the expression of free fatty acid receptor 2 (Ffar2), Ffar3 and early-stage adipogenesis. Nutr. Diabetes 2014, 4, e128. [CrossRef] [PubMed]

81. Perry, R.J.; Peng, L.; Barry, N.A.; Cline, G.W.; Zhang, D.Y.; Cardone, R.L.; Petersen, K.F.; Kibbey, R.G.; Goodman, A.L.; Shulman, G.I. Acetate mediates a microbiome-brain-beta-cell axis to promote metabolic syndrome. Nature 2016, 534, 213-217. [CrossRef]

82. Pant, K.; Yadav, A.K.; Gupta, P.; Islam, R.; Jain, A.; Venugopal, S.K. Butyrate induces ROS-mediated apoptosis by modulating miR-22/SIRT-1 pathway in hepatic cancer cells. Redox Biol. 2017, 12, 340-349. [CrossRef]

83. Rada-Iglesias, A.; Enroth, S.; Ameur, A.; Koch, C.M.; Clelland, G.K.; Respuela-Alonso, P.; Wilcox, S.; Dovey, O.M.; Ellis, P.D.; Langford, C.F.; et al. Butyrate mediates decrease of histone acetylation centered on transcription start sites and down-regulation of associated genes. Genome Res. 2007, 17, 708-719. [CrossRef] [PubMed]

84. Nakahata, Y.; Kaluzova, M.; Grimaldi, B.; Sahar, S.; Hirayama, J.; Chen, D.; Guarente, L.P.; Sassone-Corsi, P. The NAD(+)-dependent deacetylase SIRT1 modulates CLOCK-mediated chromatin remodeling and circadian control. Cell 2008, 134, 329-340. [CrossRef] [PubMed]

85. Gillum, M.P.; Erion, D.M.; Shulman, G.I. Sirtuin-1 regulation of mammalian metabolism. Trends Mol. Med. 2011, 17, 8-13. [CrossRef] [PubMed]

86. Vogelauer, M.; Krall, A.S.; McBrian, M.A.; Li, J.Y.; Kurdistani, S.K. Stimulation of histone deacetylase activity by metabolites of intermediary metabolism. J. Biol. Chem. 2012, 287, 32006-32016. [CrossRef] [PubMed]

87. Williams, B.B.; Van Benschoten, A.H.; Cimermancic, P.; Donia, M.S.; Zimmermann, M.; Taketani, M.; Ishihara, A.; Kashyap, P.C.; Fraser, J.S.; Fischbach, M.A. Discovery and characterization of gut microbiota decarboxylases that can produce the neurotransmitter tryptamine. Cell Host Microbe 2014, 16, 495-503. [CrossRef] [PubMed]

88. Yano, J.M.; Yu, K.; Donaldson, G.P.; Shastri, G.G.; Ann, P.; Ma, L.; Nagler, C.R.; Ismagilov, R.F.; Mazmanian, S.K.; Hsiao, E.Y. Indigenous bacteria from the gut microbiota regulate host serotonin biosynthesis. Cell 2015, 161, 264-276. [CrossRef]

89. Wolf, G. Three vitamins are involved in regulation of the circadian rhythm. Nutr. Rev. 2002, 60, $257-260$.

90. Beydoun, M.A.; Gamaldo, A.A.; Canas, J.A.; Beydoun, H.A.; Shah, M.T.; McNeely, J.M.; Zonderman, A.B. Serum nutritional biomarkers and their associations with sleep among us adults in recent national surveys. PLoS ONE 2014, 9, e103490. [CrossRef]

91. Magnusdottir, S.; Ravcheev, D.; de Crecy-Lagard, V.; Thiele, I. Systematic genome assessment of B-vitamin biosynthesis suggests co-operation among gut microbes. Front. Genet. 2015, 6, 148. [CrossRef]

92. Degnan, P.H.; Taga, M.E.; Goodman, A.L. Vitamin B12 as a modulator of gut microbial ecology. Cell Metab. 2014, 20, 769-778. [CrossRef]

93. Langlais, P.J.; Hall, T. Thiamine deficiency-induced disruptions in the diurnal rhythm and regulation of body temperature in the rat. Metab. Brain Dis. 1998, 13, 225-239. [CrossRef] [PubMed] 
94. Guy LeBlanc, J.; Milani, C.; Savoy de Giori, G.; Sesma, F.; van Sinderen, D.; Ventura, M. Bacteria as vitamin suppliers to their host: A gut microbiota perspective. Curr. Opin. Biotechnol. 2013, 24, 160-168. [CrossRef] [PubMed]

95. Hirano, A.; Braas, D.; Fu, Y.H.; Ptacek, L.J. FAD regulates cryptochrome protein stability and circadian clock in mice. Cell Rep. 2017, 19, 255-266. [CrossRef]

96. Wakade, C.; Chong, R.; Bradley, E.; Thomas, B.; Morgan, J. Upregulation of GPR109A in Parkinson's Disease. PLoS ONE 2014, 9, e109818. [CrossRef] [PubMed]

97. Sun, Q.W.; Yang, Y.; Li, X.; He, B.; Jia, Y.M.; Zhang, N.N.; Zhao, R.Q. Folate deprivation modulates the expression of autophagy- and circadian-related genes in HT-22 hippocampal neuron cells through GR-mediated pathway. Steroids 2016, 112, 12-19. [CrossRef] [PubMed]

98. Jiang, J.; Chan, A.; Ali, S.; Saha, A.; Haushalter, K.J.; Lam, W.-L.M.; Glasheen, M.; Parker, J.; Brenner, M.; Mahon, S.B.; et al. Hydrogen sulfide-Mechanisms of toxicity and development of an antidote. Sci. Rep. 2016, 6, 20831. [CrossRef] [PubMed]

99. Davies, S.K.; Ang, J.E.; Revell, V.L.; Holmes, B.; Mann, A.; Robertson, F.P.; Cui, N.; Middleton, B.; Ackermann, K.; Kayser, M.; et al. Effect of sleep deprivation on the human metabolome. Proc. Natl. Acad. Sci. USA 2014, 111, 10761-10766. [CrossRef]

100. Wikoff, W.R.; Anfora, A.T.; Liu, J.; Schultz, P.G.; Lesley, S.A.; Peters, E.C.; Siuzdak, G. Metabolomics analysis reveals large effects of gut microflora on mammalian blood metabolites. Proc. Natl. Acad. Sci. USA 2009, 106, 3698-3703. [CrossRef]

101. Clarke, G.; Grenham, S.; Scully, P.; Fitzgerald, P.; Moloney, R.D.; Shanahan, F.; Dinan, T.G.; Cryan, J.F. The microbiome-gut-brain axis during early life regulates the hippocampal serotonergic system in a sex-dependent manner. Mol. Psychiatry 2013, 18, 666-673. [CrossRef]

102. Versteeg, R.I.; Serlie, M.J.; Kalsbeek, A.; la Fleur, S.E. Serotonin, a possible intermediate between disturbed circadian rhythms and metabolic disease. Neuroscience 2015, 301, 155-167. [CrossRef]

103. Hardeland, R.; Cardinali, D.P.; Srinivasan, V.; Spence, D.W.; Brown, G.M.; Pandi-Perumal, S.R. Melatonin-A pleiotropic, orchestrating regulator molecule. Prog. Neurobiol. 2011, 93, 350-384. [CrossRef] [PubMed]

104. Wong, R.K.; Yang, C.; Song, G.H.; Wong, J.; Ho, K.Y. Melatonin regulation as a possible mechanism for probiotic (VSL\#3) in irritable bowel syndrome: A randomized double-blinded placebo study. Dig. Dis. Sci. 2015, 60, 186-194. [PubMed]

105. Paulose, J.K.; Wright, J.M.; Patel, A.G.; Cassone, V.M. Human gut bacteria are sensitive to melatonin and express endogenous circadian rhythmicity. PLoS ONE 2016, 11, e0146643. [CrossRef] [PubMed]

106. Daulatzai, M.A. Chronic functional bowel syndrome enhances gut-brain axis dysfunction, neuroinflammation, cognitive impairment, and vulnerability to dementia. Neurochem. Res. 2014, 39, 624-644. [CrossRef] [PubMed]

107. Malinen, E.; Mättö, J.; Salmitie, M.; Alander, M.; Saarela, M.; Palva, A. PCR-ELISA: II: Analysis of Bifidobacterium populations in human faecal samples from a consumption trial with Bifidobacterium lactis Bb-12 and a galacto-oligosaccharide preparation. Syst. Appl. Microbiol. 2002, 25, 249-258. [PubMed]

(c) 2019 by the authors. Licensee MDPI, Basel, Switzerland. This article is an open access article distributed under the terms and conditions of the Creative Commons Attribution (CC BY) license (http:/ / creativecommons.org/licenses/by/4.0/). 